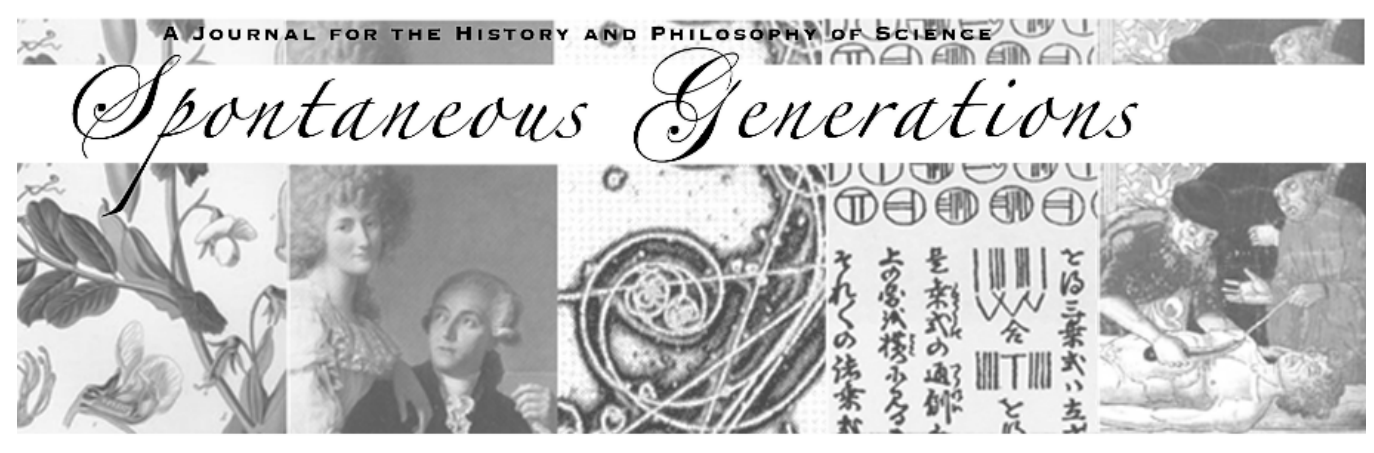

\title{
Transition to Science 2.0: "Remoralizing" the Economy of Science
}

Author(s): David Tyfield

Source: Spontaneous Generations: A Journal for the History and Philosophy of Science, Vol. 7, No. 1 (2013) 29-48.

Published by: The University of Toronto

DOI: 10.4245/sponge.v7i1.19664

\section{EDITORIAL OFFICES}

Institute for the History and Philosophy of Science and Technology

Room 316 Victoria College, 91 Charles Street West

Toronto, Ontario, Canada M5S 1K7

hapsat.society@utoronto.ca

Published online at jps.library.utoronto.ca/index.php/SpontaneousGenerations ISSN 19130465

Founded in 2006, Spontaneous Generations is an online academic journal published by graduate students at the Institute for the History and Philosophy of Science and Technology, University of Toronto. There is no subscription or membership fee. Spontaneous Generations provides immediate open access to its content on the principle that making research freely available to the public supports a greater global exchange of knowledge. 
Focused Discussion

INVITED PAPER

\title{
Transition to Science 2.0 'Remoralizing' the Economy of Science
}

\author{
David Tyfield ${ }^{\dagger}$
}

\begin{abstract}
The present is a moment of crisis and transition, both generally and specifically in "knowledge" and its institutions. Acknowledging this elicits the key questions: where are we? Where are we headed? What, if anything, can be done about this? And what can the "economics of science" contribute to this? This paper assumes a "cultural political economy of research \& innovation" (CPERI) perspective to explore the current upheaval and transition in the system of academic knowledge production, at the confluence of accelerating commercialisation and the seemingly opposing movement of "open science." This perspective affords a characterisation of the core of the current crises as a crisis of moral economy; an issue to which a political economy of epistemic authority is in turn crucial. A "remoralizing" of knowledge production is thus a matter of key systemic importance, though it is important to understand such developments in power-strategic, and not explicitly moral, terms. Much of the current moves towards "open science" and "massively open online courses" (MOOCs) can also then be seen as self-defeating developments that simply exacerbate the crisis of a viable "economy of science" and in no sense its solution. Their lasting significance, however, is more likely to lie precisely in their effects on the construction of a new moral economy of knowledge production.
\end{abstract}

\section{INTRODUCTION}

Almost everywhere one looks today regarding issues of political economy, knowledge (science \& technology, research \& innovation) and their interaction, there appears to be one, or rather, many crises. Some of these are the focus of headlines and newspaper leaders-notably the ongoing economic depression and the host of ecological and technological challenges that are usually discussed in terms of climate change-while others are the more recondite preserve of specialists, albeit perhaps with a broader "policy" relevance (e.g. concerns regarding a dwindling innovation competitiveness vs. the resurgent powers of the "global South"). Moreover, it is increasingly clear that many of

* Received 19 May 2013.

$\dagger$ David Tyfield is a Lecturer and Co-Director of the Centre for Mobilities Research (CeMoRe), Sociology Department, Lancaster University. His research focuses on the interaction of political economy, social change and developments in science, technology and innovation, with a particular focus on issues of low-carbon transition in China and the life sciences. He is the author of The Economics of Science (Routledge, 2012 in 2 volumes). 
these crises themselves, or at least ongoing attempts to resolve them, intimately involve the continuing penetration of society by interactive social media ("web 2.0") and associated technologies of "big data" analysis (Mayer-Schönberger and Cukier 2013). Regarding science, these issues notably include "open access" publishing, broader "open science" initiatives and the new hype regarding "massively open online courses" (MOOCs).

In this context, it is unsurprising that interest in a literature on the "transition" of "socio-technical systems" has surged (Geels 2005, 2011; Elzen et al. 2004; Smith et al. 2010). Most of this literature focuses on industrial/consumer systems and charts both their former transitions to their current incarnations and-the source of their current policy resonance-the prospects of and obstacles to future transition, especially to "low-carbon" or environmental sustainability. Its core, and compelling, argument is that a transition is never just a matter of the introduction of new technologies (let alone a single technology), but is a hugely complex socio-technical (and thus economic, political and cultural) process involving the parallel realignment of multiple agents, factors and practices, i.e. of a whole system. As such, there is a prima facie improbability of systemic disruption from any specific innovation or new technology, given how much else in society must be rearranged, coordinated and coproduced, and in the face of resistance at all levels, not least from the incumbent system and its major beneficiaries.

Regarding the economics of science, this literature features in its framework the specific sciences and research institutions relevant to the "system" under investigation, generating the theoretical expectation that these must evolve in parallel with the broader change of the system. Given both the large and striking differences across the disciplines today-the so-called disunity of science (Dupré 1995)-and the increasing hybridity of research itself as "technoscience" (Nordmann et al. 2011), this focus on the transformation of specific sciences in their specific context of relevance is both entirely defensible and capable of yielding important insights in the transformations of the "economics of science." However, such are the challenges to the core of the scientific knowledge production (and circulation and reception) that are now underway, that a similar analysis seems warranted for (academic) "knowledge" as a whole, or more generally, for the broad enterprise of knowledge production that is today conventionally centred on the university. Acknowledging this as a moment of crisis and transition, both in general and specifically regarding "knowledge" and its institutions, elicits the key questions: Where are we? Where are we headed? What, if anything, can be done about this? And what can the "economics of science" contribute to this?

Starting with the last of these questions, clearly it depends on how the "economics of science" is conceived. Here we shall assume a cultural political economy perspective (CPE)-as argued elsewhere (Tyfield 2012a, 
b)-to investigate this moment of socio-technical system transition and its tendencies. This involves analysis of the interaction between-or the parallel co-production of-the specific systems of the production, utilisation and funding of ("scientific") knowledge, and the broader technologies of government (in the Foucauldian sense) for the management of liberal states and the regularisation of capital accumulation (Tyfield 2012c).

Such a perspective affords a characterisation of the core of the current crises as a crisis of moral economy, i.e. of a popularly accepted moral order that legitimates the given distribution of the fruits of human labour as at least approximating due reward, given the contribution of their recipient. Yet this in turn explains the particular importance of the crisis of knowledge production, for there is an intimate and crucial connection between such a moral economy and the production of socially-validated and socially-valued "knowledge." In other words, a transition in knowledge production is not "just another" case study, but one of specific and central importance to a broader analysis of "system transition."

\section{From the Crisis of Neoliberal Science to California Dreaming}

The global(izing) political economic dominance of neoliberalism in the past few decades has undoubtedly transformed the "economics of science," with research and innovation both as key targets for the more general programme of commercialization and corporate accumulation by dispossession, to use Harvey's (2005) terminology. Indeed, the resurgence of interest since the mid-1990s in the "economics of science" was precisely in response to the intensifying encounter of academia with market-based demands (Sent 1999). Since then a voluminous literature has emerged, praising, criticizing and explaining the commercialisation of science, which we make no effort to summarize here (Mirowski and Sent 2002, 2008; Tyfield 2012a). Rather, our starting point is the specifically neoliberal model of research, innovation and higher education that has emerged, most profoundly in the Anglo-Saxon countries at the core of the global financialized economy, and the extraordinary challenges it is increasingly facing.

These are inseparably crises of both the production and circulation of knowledge-i.e. regarding the "use value" of the products of the university-and of their economic viability-i.e. regarding their "exchange value." In relation to the "use value," increasing enclosure of knowledge-especially in fields like the life sciences that have been most actively pursued on the promise of innovation super-rents-has indeed generated intensifying and self-defeating problems of knowledge sharing (Heller \& Eisenberg's (1998) "anti-commons"), while biotech-pharmaceutical pipelines continue to dry up (Mittra 2012; Heller 2008). Moreover, as genomics, for instance, reveals a biological reality that is hugely more complex than that envisaged, the problems of sharing data become 
even starker: fundamental progress in tackling these scientific problems calls for even greater sharing of information and findings. This impales neoliberal consumerist imaginaries of "personalized medicine" on the horns of dilemma: sacrifice the market of genomic information for some sort of pooled and open knowledge base, or give up all talk of a genomic revolution in healthcare.

As regards the latter-the "use value" of university knowledge products-the crisis of financialization also has profound implications for the economic viability of existing models of both research and higher education. Public universities have been strangled by fiscal austerity, and both public and private universities have found themselves with unsustainable levels of debt taken on in the "good times" for the expansion of both research and student-attractive leisure facilities (Economist 2012a), as knowledge has become a commodity. Moreover, those relatively few universities that have been enormous winners of the globalized, financialized competition, with large endowments and/or patent/intellectual property portfolios, have also suffered drastic devaluations in their financial assets (Christensen and Eyring 2011). The tightening of university/departmental budgets has also dramatically transformed the career structure, resulting in ever-diminishing chances of tenure or a permanent position of some description. Instead, junior faculty are increasingly adjuncts (76\% of US faculty in 2013) hired on short-term contracts with little if any institutional financial support for the increasingly difficult task of building a research profile and attending conferences, which in turn serve as the arenas for future hiring opportunities (Kendzior 2012, 2013). And these adjunct faculty are themselves increasingly weighed down with debt-in the United States, student debt is the only form of debt that one cannot even escape by bankruptcy. Moreover, as research becomes increasingly competitive, it becomes cost-ineffective for permanent staff to teach undergraduates, this task being handed over to the adjunct doctoral and post-doctoral teaching assistants (Christensen and Eyring 2011). Yet the cost of student fees-and hence yet again, debt-incurred by undergraduates continues to grow, leading on the one hand to ever greater grievances from this crucial "customer" of the universities and on the other to a "student loan bomb" (Kiplinger 2012).

In short, regarding both the generation of "the goods" and the "value for money" (and thus financial viability), this neoliberal model is increasingly and manifestly dysfunctional. What, then, is likely to happen? What could follow this neoliberal model? An emergent answer to this question, garnering growing interest especially amongst policy circles, is the cluster of innovations that congregate around the discourse of "open science" and "online education." And indeed, partly as a matter of self-fulfilling policy initiative, there is increasing evidence of such initiatives across research, the connection between research and innovation, and higher education. These, however, must be understood not merely as coincidental developments but as tendencies responding to the 
immanent tensions and challenges of the neoliberal model of the "knowledge economy."

These initiatives augur-and explicitly promise-profound transformation across the full range of processes involved in the production and circulation of knowledge centred on the university. For instance, following the lead of emerging practices in the life sciences and, to a lesser extent, physics and maths, the United Kingdom is rushing into effect a wholesale transformation of the economics of scientific publishing towards "open access" (OA) (Finch 2012). Instead of the existing norm of a "reader pays" system-leading to institutional subscriptions so that individual (but institutionally-employed) researchers do not face unpayable fees to access the articles needed for their research-OA demands that articles are all made free to the reader. In an age of (supposedly) ubiquitous internet access, the argument goes, it is both ridiculous and unjustifiable that such knowledge should circulate behind walls (and thereby make significant profits for the publishing companies). OA, then, opens up the resulting research to everyone ("tax payers"), not just those whose employment confers the benefit of the institutionally paid-for access, with the promise of "democratizing" science.

Moreover, the "democratization of science" has particular resonance given the broader discourse of "open science," in which the very process of scientific problem solving (of a certain specific sort-see below) has been shown to work extremely well-arguably even more efficiently-by way of open web 2.0/wiki real-time conversation amongst self-selecting groups comprising both "professionals" and "amateurs" (Nielsen 2012; Royal Society 2012). Taken together with OA, then, it is argued that unlocking all this scientific knowledge will allow the full potential of human scientific ingenuity, wherever it may be, to be actualized. Finally, the online "revolution" is also seen to be an unstoppable tide in higher education; both cheaper, more "learning outcome"-focused for-profit universities/colleges and (particularly since 2012) MOOCs, offering individual courses for free, are seen as presenting an increasingly disruptive wave of innovations (Daniel 2012; Edgecliffe-Johnson and Cook 2013; Cadwalladr 2012).

It is clear that much of the heightened interest in and response to these initiatives may itself be explained not so much by a sober assessment of their potential as by the growing appreciation among institutional leaders in the university and policy sectors of the intractable problems of the existing model. Moreover, these interlocking "open" and "online" initiatives boast a series of important strategic strengths, three of which stand out in particular. First, they are instances of-and thus have the backing of-a much broader ideological movement, which may be called the "Californian ideology," in allusion to its geographical spiritual home amongst the free software/open source ("FLOSS" (Berry 2008)) libertarian hactivists and 2.0 web entrepreneurs 
of Silicon Valley (two of the major MOOC companies, Coursera and Udacity, are both spin-offs from Stanford). This provides its advocates not only with a highly developed argument but also a broad activist community of backers. Second, this community of backers is itself already highly (spectacularly!) wealthy and powerful, as epitomized in the corporate person of Google. Finally, its proponents describe the benefits of open science (in its various guises) in highly experiential and affective-even spiritual-terms; they speak of epiphanies, "wow moments" and life-transforming experiences in reference to their original lay participation in the communal solving of a tough mathematical problem, the greater satisfaction of blogging or open publishing, or the participation (as student or teacher) in MOOCs (Nielsen 2012; Cadwalladr 2012). In short, "open science" generates "true believers" to whom the continuing "revolution" of science can be entrusted.

Yet this "open science" is also being met by growing numbers of sceptics, naysayers and critics. For instance, the UK's headlong dive into OA publishing has raised multiple objections regarding the implications for scholarship and its career structure, which are hard to dismiss as the special pleading of a conservative "producer" interest-group (Disorder of Things 2012; Harnad 2013). For instance, with readers no longer paying, the costs of publishing (short of a full-scale move to "free" online publishing, which seems unlikely in the extreme and is not favoured by policy) must instead pass to the article's author(s)-the so-called "gold" model. Alternatively, neither reader nor author pays, but the journal may withhold unpaid access for a given (short) period after first publication (e.g. 12 or 24 months) in the hope of amassing institutional subscriptions from those who cannot wait-the "green" model.

Both cases, however, entail the introduction of an economic model with far-reaching and as-yet-unclear implications both for publishing itself and for the multiple institutions that underpin the production of such research in the first place-including not just universities, but also non-profit disciplinary academies or learned institutions that may generate significant income from publishing journals (Trueman 2013). At the very least, a wholesale shift to the gold model (as the UK government currently favours) will inevitably introduce a level of institutional oversight (which need not be disciplinary peer review) to assess which articles the university should and should not pay to publish. This will thus create significant inter-departmental and staff tensions (e.g. senior vs. junior faculty) that could well destabilize whole institutions, especially as all estimates to date show that current institutional budgets of British universities could not possibly cover even existing (let alone future increased) levels of publication (Trueman 2013). Gold OA will also, ironically, exclude from publication anyone not employed by an institution that is willing to pay for the publication of their research-i.e. the very opposite of the avowed intention of "democratising" science-but in ways that would exclude emeritus faculty, those 
passing between positions, and junior (adjunct teaching?) faculty, not just the proverbial lay enthusiast.

Similar objections to the economic and epistemic (i.e. regarding their effects on their ostensible goal of encouraging greater dispersion of, and higher quality of, knowledge and education) viability of MOOCs as a new model of mainstream higher education are also easy to formulate (Hill 2012). For instance, even as established universities sign up to deliver MOOCs as partners of MOOC initiatives, both private (e.g. Coursera, Udacity, EdX) and public (the UK's FutureLearn), their free provision and universities' generalized refusal to count such courses towards a degree highlight how far MOOCs remain from an economic model capable of sustaining generalized higher education (Daniel 2012; Hill 2012).

Seen in this light, it may seem baffling that there is any interest at all, let alone such intensive interest, in these initiatives: surely they offer no prospect of a generalized transformation in the "economics of science" until they can answer such fundamental questions. Yet this is to underestimate, or least to misunderstand, the Californian ideology underlying such initiatives. For its proponents, the experience of neoliberal and financialized innovation in recent decades has been precisely the vindication of the mantra that one need only take care of the open source product or service and the business model will take care of itself in good time (e.g. Hern 2013)-not least through the financialized realization of spectacular wealth with an IPO flotation on the stock market. With example after example of such a model, why should open science be any different? Moreover, the more techno-utopian of its advocates are committed to a vision-which they see being realized-of the creation of a post-human(ist) techno-knowledge network in which information itself, as a global "data web," "wakes up" (Nielsen 2012). From such a perspective, the utopia emerging via open and online network architectures will unleash such a cornucopia of information-based wealth that prosperity will be effectively limitless and ubiquitous, rendering "payment" for anything redundant, indeed inconceivable-an historical relic of an idea ( $C f$ Larnier 2013).

There is evidently insufficient space to unpack such arguments here. From a CPE perspective, however, the key error here is the superficiality of its analysis of the "economics of science," specifically because it separates "science" (or "knowledge," too often identified with data or information) and "money" into a strict dichotomy. This is read by many (not just "open science" enthusiasts, but also the diverse opponents and critics of neoliberalism) as a critical move, as it appears not only to reinstantiate a dualism that neoliberalism's commercialisation of the academy has attempted to collapse-in which case "good science" would simply be science that "the market" chooses to "buy"-but then, further, to take the side of "science" vs. "money." But the "Californists" are peculiar and unlikely revolutionaries, as already described, and this is 
clear in the conceptualization of their core project. For, rather than licensing a critical or radical rejection of commercialisation of knowledge production, this fundamental distinction of science vs. money in turn licences, and/or is underpinned by, an utter neglect of questions about the interaction of power and knowledge and about their concentration, in the institutions of both "politics" (i.e. states) and "economics" (i.e. corporations and financial assets).

The absence of "power" in their analysis is a descriptive/explanatory, pragmatic and normative failing. It is an explanatory gap in that the trajectory of any future system transition will be inexplicable without reference to power (see below). And it is a pragmatic and normative problem in that it argues for a future that is both socially problematic and manifestly self-defeating. As poacher-turned-gamekeeper Jaron Larnier has argued (2011, 2013), the strict money vs. science distinction of the "open science" argument can underpin an emerging political economy of knowledge (and of human creativity more broadly) that tends continually to undermine the compensation of human knowledge labour-albeit under the seemingly democratizing banner of "free information"-upon which such a system is entirely dependent. Furthermore, this analysis not only thereby destroys the "livelihoods" of a genuinely "creative" "knowledge-based economy" but also sponsors the construction of a system characterized by even more concentrated corporate control of knowledge (eg. information, data) than that of the IP-intensive corporate model of neoliberalism it ostensibly subverts.

The beneficiaries of this new knowledge political economy are thus overwhelmingly the four corporate giants of the web 2.0 internet age-Amazon, Apple, Facebook and Google. These companies have assumed such dominance by forging uniquely enabled network positions that can harness the "free labour" of billions of users (or "prosumers")-possibly infringing intellectual property rights in the process, exploiting counter-cultural "free information" cachet in the process-and then control and monetize the resulting "big data" sets of information with exceptionally proprietorial business models. Finally, the emergence of such corporate concentration of power (not just financial, but also involving power over knowledge and its production and circulation) is immunized from critique precisely because of the strict conceptual separation of "science" and "money," which places these "free information" companies firmly on the side of the angels.

The Big Four (e.g. Economist 2012b) have unprecedented leverage over the emerging political economy of knowledge, given its control over various sectors: Amazon (not just e-commerce, but also e-publishing); Facebook (with social media and associated technologies of "social search" and mapping, hence day-to-day knowledge and consumer choices or recommendations); Apple (the products of "creative industries" via iTunes, etc.); and, most of all, Google. Not only is Google driving the development of increasingly indispensable 
portals for the access and search of scholarly writing (viz, Google Scholar, Google Books, Google Docs for collaborative drafting and arguably Google Translate), but it also has fingers in numerous "open science" pies, including the personal genomics firm 23andme (run by Google's Sergei Bryn's wife) and its project of "Research 2.0," in which 23andme customers are encouraged to participate in research both by contributing their genomic data and by participating in associated web 2.0 "open science" projects that the company then owns. Other Google initiatives include the development of real-time data regarding outbreaks of infectious disease, by using "big data" correlations with geographical clusters of specific Google search terms; an interest in MOOCs; or as a paradigm example of "data-driven intelligence" (Nielsen 2012). Yet, for all this ubiquitous presence of corporate behemoths, discussion among "open science" (or "data web") advocates is marked by the glaring absence of any discussion of corporate power or, at most, its sanguine presumption that corporations are essentially benign (e.g. Nielsen 2012; Naughton 2013; Schmidt and Cohen 2013).

This Californist "open science" discourse proposes an economics of science destructive of a political economic system that could sustain the (professionalized) production of such knowledge. Furthermore, it is premised on a system characterised (with increasing transparency) by a fundamental break between its explicit values of openness and mass participation and its actual political economic structure of historically unprecedented corporate concentration, mass redundancy and professional insecurity of actual "knowledge workers" (and-an explosive scandal in the UK and then US in May 2013-off-shore tax avoidance, forcing even a newspaper editorial from Google's executive chairman, Eric Schmidt (2013; Bowers and Syal 2013) in response). These issues come together as a matter of moral economy.

\section{Liberalisms and the Moral Economy of Science}

By "moral economy" we mean here the conjunction of the system of the distribution of economic gains and compensation with a generalized sense that such allocation is a reasonable reflection of the effort and social worth of any given individual's specific contribution or labour; in other words, that the "economy" is "moral," justified by the "fair shares" that are its outcome. From a CPE perspective, one may expect that any reasonably durable and stable form of life depends upon such a moral economy to sustain acceptance of what would otherwise be challenged as inequalities and injustices of outcome. Yet such a moral economy is all the more important for a capitalist society given both the central importance of "the economy" to its specific form of social order and the "inherent improbability of capital accumulation" (Jessop 2002). Capitalist societies thus depend upon a specific and concrete settlement to deflate, albeit always only temporarily, the multiple contradictions of capital that are insoluble 
in the abstract. And, indeed, establishing such a rational justification of the distribution of wealth within a capitalist society has been the primary task of "economics" ever since the classical political economy of Smith and Ricardo (Clarke 1982).

A crisis of moral economy, therefore, involves the emergence of a conjunction in which wealth and poverty compound in ways that are met with popular disillusionment and anger rather than enthusiasm and/or acceptance. And as this in turn threatens to undermine the political economic settlement upon which continued capital accumulation rests, such a crisis also thereby spells an existential test for any such political economy. A crisis in the moral economy of knowledge production, however, is not merely another example of such a crisis, but one that is of specific importance and systemic significance for a broader regime of liberal government and regularization of capitalist economies. This is due to the central importance, in the context of modern liberal societies, of "rational" knowledge in such a "moral" order and, conversely, of moral and social authority in stabilizing a specific model of knowledge production.

By "liberal" here we are referring to a specifically modern form of the government of societies centred on the construction of new human freedoms (formally universal, substantively limited) expressive of the core value of individual autonomy. Yet both the intelligibility/legitimacy of this form of government and its actual administration depend utterly on knowledge-technologies and their purported epistemic authority that render it not only "rational," but also "unarguably" so, to conduct oneself in certain ways conducive to social order. But this in turn demands a social system for the production of knowledge that is itself popularly understood (not least by those individuals and groups formed and empowered by this very system) as rational and hence socially/morally defensible. A key element of such a judgement is whether or not the system adequately compensates those involved in the production of such knowledge, so that the system can sustain processes of knowledge production and circulation. And this in turn legitimates the given social bargain of compensation for those producing knowledge, which contributes to this moral vision of society.

In fact, for liberal regimes the primary epistemic issue regarding generalized government of a society is not the specific mechanisms of science and/or professional "knowledge production" but rather the social mechanisms that are understood to make the best decisions in order both to instantiate individual autonomy and to ensure social order. For liberal regimes, the key institution here is the market, the limits it imposes on state (or other forms of hierarchical) power and conversely its own limits (if any), such that the core paradox of capitalist economies-namely how exchange at ("fair") value nevertheless generates profit(s)-may be considered "resolved." The specific assessment of the market, however, may (and has historically) change(d): for instance, classical eighteenth 
and nineteenth century liberalism conceived of the market as the "natural" result of man's (sic) "propensity to truck, barter and exchange," such that laissez faire would simply open up the possibility for the spontaneous emergence of markets. Moreover, where markets do not thus emerge, due to "market failure," the state has a legitimate, but strictly circumscribed, role to play. Conversely, neoliberalism conceives the market as in need of active construction with the assistance of state power. Such projects of construction are imperative, however, because the market is essentially unlimited as a mechanism for social decision-making, so that "market failure" demands correction of the market rather than its replacement by public provision (Mirowski 2011).

The moral economy of liberal regimes is thus intrinsically epistemic and primarily justified in epistemic terms. Yet the moral economy of knowledge production per se remains an issue of central-indeed, pivotal-importance, even as it may be seen as a relatively peripheral "sector" of "the economy." For a system of social government and decision-making cannot simultaneously be judged to be optimal and rational while also producing transparently irrational and dysfunctional results in the very production and circulation of "rational" scientific knowledge. Hence, a crisis of moral economy of knowledge production is like an infection affecting an artery or taproot of the entire "body politic" and passing swiftly to a judgement regarding the epistemic validity-and hence morality or fairness-of the core epistemic mechanisms of liberal society more broadly, i.e. the market as currently conceptualized. In other words, regarding the specific example of neoliberalism, if a "marketplace of ideas" is manifestly viewed as dysfunctional, it undermines not just a particular conception of how to organize science ("a marketplace of ideas") but rather the very foundation stone of the edifice of the power regime of neoliberal government per se ("a marketplace of ideas" and of all things): for how can the market any longer be trusted to be the optimal decision-maker and epistemic mechanism when it evidently fails as a mechanism for the production of knowledge?

A crisis in the moral economy of knowledge production, therefore, entails a judgement that the current system of knowledge production is itself irrational; and this in turn spells the unravelling of a fundamental thread of the moral economy of the liberal government of capitalist societies per se, without which it loses all credible claims to be "rational" and thus fair in its economic outcomes. This foundation stone, therefore, of "rational" liberal government-by-freedoms is the specific "economy of science" of the credit/reputation system, understood in its broadest sense as an epistemic economy, which includes peer review, referencing and citations, competitive grants, and the assessment and attribution of scientific status. From this perspective, the credit/reputation system is not merely a slightly unhealthy fascination of the ambitious professional researcher. Rather it is a social system that serves the crucial governmental role of administering and legitimizing the 
actual funding of the social production of knowledge and its social and economic integration, in turn affording the "going-on" of a liberal power regime. The credit/reputation system, qua moral economy in liberal society, is thus primarily tasked with the knowledgeable assessment of the production of knowledgeable people.

Such a definition captures two inseparable elements of this system: first, what must be, for such knowledge to be judged "rational" and "scientific" and thus act as moral support for liberal government, intrinsic criteria of the assessment of knowledge on its own terms; and second, the irreducible socio-historical situatedness and hence extrinsic social criteria of what may be taken to count as "knowledgeable," not least in the sense of such knowledge being of "value" to society, and how this attribution of value hinges on the production of (specific, socially situated) people, not an abstract thing called "knowledge." From a political perspective, "science" (a system of credit/reputation) primarily produces scientists, not science (i.e. scientific knowledge). It also highlights how any given settlement of the meaning of this definition is irreducibly saturated with power. The first thus excludes marketing and public relations, the latter astrology. Furthermore, this system of knowledge production must also act as a measurement technology that affords the bridging between the sui generis assessment of individual knowledge contributions and their levels of economic reward, i.e. as the moral economy of science. For it is evidently the case that science must be funded and on some basis. And again, those disciplines that are thus rewarded are thereby empowered for the future "rational" legitimation of their social and epistemic standing. From this perspective, however, it is clear that how and to what extent specific knowledge projects are funded is irreducibly a cultural and political issue-connected to the understanding of the nature of knowledge and its production, how and what knowledge is of value and for what liberal governmental purposes-and never just an "economic" one.

Finally, focusing on the assessment of the production of knowledgeable people, hence knowledgeable labour power, thus includes not only the processes of research and the construction of researchers and research careers but also those of higher education. For it is in higher education that attainment of knowledge of broader applicability "in society" receives the all-important stamp of approval from the "knowledgeable assessors"-experts in the relevant field who have themselves completed socially-defined apprenticeships and bear the marks of this attainment.

Such a widening of definition is crucial because it presents the broader social significance of institutions of higher learning and the crucial, and possibly divergent, imperatives that the system of knowledge production must juggle as a system. In other words, the "economics of science" must be understood as a system of materialized, socio-technical practices that underpin and are 
performed as a distinctive moral economy. Moreover, from this perspective we can begin to explore the concrete mechanisms through which a crisis of moral economy of the production of knowledge can "infect" the rest of the given liberal regime of government. Collapse of such a moral economy in turn undermines the creation of both the knowledge and the specific forms of knowledgeable labour power demanded across the society and economy. And conversely, we can see how a transition in the production of knowledge must itself be a systemic, not piecemeal, change, and how such a transition in turn raises profound questions about broader transition in the liberal power regime.

For instance, as regards the former, this systemic perspective undermines arguments (both boosterism and jeremiads) that look one-sidedly at specific issues in the transformation of the economy of knowledge production, such as how web 2.0 is going to transform "science"-defined as mathematically solvable problems, with no comment regarding sciences tackling more engaged or "complex" problems, let alone the humanities (Nielsen 2012)-or undergraduate teaching, defined as measurable learning outcomes desired by business employers using increasingly sophisticated online "learning analytics," with no mention of their relationship to "research" or scholarship of those supposedly accredited with conducting such assessment. Conversely, this systemic perspective highlights how any sustainable systems transition depends on the forging not only of an acceptable division of epistemic labour, regarding the emergence of new sites for research in existing fields and disciplines. Transition also demands a new accommodation of the immanent connection between the development of new knowledge (according to the internal norms of a specific discipline or field of knowledge) and the teaching and accreditation of the next generation of scholars, professional-practical users of this knowledge and/or lay citizens appreciating the intrinsic and moral/ social/ aesthetic value of this learning-and thus willing to support it as "tax-payers," alumni or investors.

Moreover, as a crisis of moral economy we can also see how there must be a new, newly acceptable division of epistemic labour not only between the "academic" and the "practical" aspects of specific "useful" sciences, but also (which is crucially overlooked) between these "useful" sciences and "useless" subjects, often in the arts or humanities (Collini 2012). It is the latter in particular that are tasked with producing and popularly disseminating the vital (and critically interrogated and robust) knowledges of legitimation of the emergent system.

On the other hand, regarding the inseparable interconnection between a transition of knowledge production system and the broader liberal power regime and moral economy, this systemic perspective highlights what is systematically overlooked in Californist accounts; namely that a viable system of knowledge production (including higher education) needs a cultural political economy that has jobs for the graduates-and sufficiently well-paid, rewarding and secure 
jobs (including in academia itself) to be able to pay down the debts of higher education and/or be worth the bother of taking courses at all-not just cheaper courses producing "appropriate skills." Again, this thus makes any system transition in knowledge production today inseparable from a broader transition in political economy that tackles the crisis of youth unemployment across the global North (Economist 2013) with the emergence of new and vigorous industries that create more jobs than they destroy; something the internet and web 2.0 has singularly failed to achieve to date (Larnier 2013).

A systemic perspective thus promises a more balanced analysis of the prospects of specific, possibly "disruptive" (Christensen and Eyring 2011), innovations in knowledge production than accounts that focus on these "open science" innovations alone. But such an account must also be alert to the central importance of power, conceived as a productive and normatively ambiguous social force-an important gap in much of the systems transition literature (Smith and Stirling 2007; Kern 2011). For it is only in the reconfiguration and production of new powerful groups that a transition can both emerge, in competition with existing "locked-in" systems, and then sustain itself.

This, again, is particularly important for a system of knowledge production (and analysis of transition thereof). The system's self-sustaining dynamic hinges on socially authoritative judgements regarding attainment of knowledge achievements (whether novel research or training to an appropriate standard) that are made by powerful groups, while also forging and reproducing these powerful groups precisely by way of their control over the production and circulation of such knowledge. As such, they are the chief beneficiaries and guardians of a new "common sense,"-hence a new moral economy-and thus the driving force behind its construction. However, stabilization of such "common sense," i.e. system transition, goes far beyond the construction of self-legitimizing explicit knowledge claims and the technologies and institutions that produce them. Rather, insofar as it is a liberal power regime, stabilization also involves the discursive-material, socio-technical redefinition of core philosophical conceptualizations and commitments regarding ontology, epistemology and science, "nature" and humanity, economic "progress" and "the good life."

For instance, liberalism (as government through freedoms) hinges on the popular (and powerful) appeal of its central claim regarding the human individual as both ontologically and morally the relevant unit and starting-point for reasoning about society. Yet what is the human individual in an age of web 2.0 social networks and (possibly cyborg) bodily and mental enhancement? This question alerts us to the key role of profound conceptual shifts-themselves in the form of a constellation or system of interlocking and relational redefinitions that must shift in toto to a relatively stable new configuration-that constitute such a new and uncoerced "common sense" moral economy which is both 
newly powerful and "rightly" or "rationally"so. And this is, in turn, the core of a system transition. There is, however, no abstract solution, no a priori Platonic blueprint, to guide such rearrangements of understanding. Rather, both any such transition and its subsequent stabilization is irreducibly a power-laden process in which the shift occurs precisely to the extent that it specifically empowers the group who stand to benefit most from it, and to the extent that those resisting it are disempowered and/or can be marginalized.

In sum, then, the ongoing crisis in knowledge production may be most productively analysed by attending to evidence of the emergence of new groups, powerfully enabled by knowledge technologies and socio-technical practices emerging simultaneously, who are transforming fundamental philosophical concepts that together could support a systems transition in the moral economy of the production of knowledge, and thence of liberal government more generally.

\section{Towards a New ‘Knowledge Economy’ Systemic Settlement}

From this perspective, let us now return to a brief assessment of "where we are." First, it becomes even clearer that the neoliberal project is now bust across the multiple levels of a system of knowledge production and its moral economy: economically, as the funding models of the broader credit/reputation system of research and education unravels; epistemically, as the failure of neoliberal economies of research to tackle global crises with meaningful breakthroughs becomes ever more grave, while those of teaching are met with increasing disgruntlement from students, future employers and (adjunct) teaching staff alike; and morally, in that luck and status, and not effort and talent, are increasingly seen as the definitive factors in educational and/or knowledge-professional success. While neoliberalism remains "strangely non-dead" (Crouch 2010) and still dominant or even resurgent (Mirowski 2013), it is also essentially broken, denuded of any broader social legitimacy and, as such, vulnerable to the emergence of any alternative liberal project capable of coalescing a broad coalition and a redefined moral vision.

In this respect, a central problematic for transition in such a liberal system and the emergence of any such alternative is the reinsertion of the autonomous individual (suitably redefined) at the heart of the system's moral self-presentation. This is a prerequisite of the establishment of a new restabilized settlement because of the central importance of the autonomous, thinking individual as the locus, in liberal societies, of moral judgement and thus also where descriptive and normative judgement-epistemic and moral economies-come together. Moreover, in moving "beyond" neoliberalism and its palpable irrationalities, such a transition depends upon an explicit repudiation of neoliberalism's epistemology. This is its epistemic market foundationalism, which judges the super-human information processor of the market to be both epistemically-and hence morally-superior to the (rational Homo Economicus, 
let alone fragile, somatic, encultured and cognitively limited actual human) individual. Thus while the crisis of neoliberalism more generally is manifest in terms of economic dysfunction, the collapse of this power regime is finally precipitated via growing popular refusal to accept the diminution of one's personal moral status (reflected in a moral economy of now demonstrably unfair compensation) vis-à-vis a market that is not only failing economically but also manifestly failing epistemically; i.e. irrational, prejudiced, stupid, ignorant, blind, etc.

Moreover, it is clear that the utopian (or dystopian, depending on one's position) visions of Californist "open science," or what may more broadly be called "Googliberalism," themselves have no prospect of achieving this. Rather Googliberalism is itself highly (not just inherently-as are all settlements in the longer term) unstable because it essentially leaves intact (or rather radicalizes) neoliberalism's account of the market as super-human information processor, most spectacularly in its post-human discourse of the "waking up" of the internet. Yet, as we have seen above, one needs only to ask the more humdrum question of "where are the jobs?" to see that the focus in such accounts is firmly at the system level of the global "data web" and the accelerated "progress" of "science" while totally neglecting that of the human individual and his/her place in such a society. It thus fails (and is likely to be seen to do so relatively quickly) precisely the test of moral economy that has triggered the breakdown of the passing order and the pursuit of transition to another: it massively rewards the undeserving and impoverishes the many and fails to deliver the "goods" of more, better and more-democratically-engaged knowledge that tackles the urgent and "wicked" problems of the multiple environmental, health and resource-based crises.

Yet this is not in any sense to argue that the Googliberal vision and Californist movement is without significant effect as regards the system transition. Indeed, while it can only be a temporary and rapidly self-destructive reality, it is a crucial element, social force and way station in the overarching trajectory of system transition. For it has not only transformed the political debate, bringing the crisis of neoliberalism's proprietorial economy of science to a head; but it is also a movement that, bolstered both by its powerful emergent knowledge technologies and the strong affective experiences of epiphany these generate for many, can boast a committed and growing hardcore of activist supporters. Yet not everyone in the world, and, more importantly, not everyone in existing positions of power is a "geek," delighting in the communal solution of chess or maths problems. The key front, therefore, on which these web 2.0 and open science initiatives, conceived as power technologies, may be expected to have the greatest and most profound effect in the course of a systems transition is in setting the questions, the agenda, if not the outcomes, in the broader, contested redefinition of the philosophical worldview underpinning a new moral 
economy.

As such, the new post-transition settlement may well be informatively described as a"liberalism 2.0" in that it is both a settled liberal moral economy and one firmly based on web 2.0. This is a new power regime and associated moral economy of knowledge production. And it will be emergent to the extent it has laboriously constructed the socio-technical systems, powerful coalitions and revised philosophical concepts that afford, at least for a broad-based coalition of the newly powerful, opportunities for individual advancement and new freedoms; new freedoms that make full use of the various potentials for "open science" and web 2.0 in terms of "progress" in standards of living, knowledge and knowledgeable social action. And, of course, one that does so in ways that also furnish new ways to "rationally" justify those who are excluded from these benefits.

There is, of course, no guarantee that such a restabilized settlement will emerge or is even possible. Indeed, such a re-established settlement for the "economics of science" remains a way off, and will not be achieved without significant social, political, cultural and possibly military upheaval via a turbulent, power-laden and morally contestable process. We are, indeed, merely at the start of a protracted process of "transition"'in the economics of science-and this will not be amenable to shortcuts by way of abstract blueprints and academic definition. The perspective outlined above, however, does at least alert us to the bare bones of what a new settlement may look like and how it may emerge-and, thus, in turn, of strategic points of intervention.

\author{
DAVID TYFIELD \\ Sociology Department \\ Lancaster University \\ Lancaster, LA1 4YN \\ United Kingdom \\ d.tyfield@lancaster.ac.uk
}

\title{
REFERENCES
}

Berry, D. 2008. Copy, Rip, Burn: The Politics of CopyLeft and Open Source. London: Pluto Press.

Bowers, S. and R. Syal. 2013. MP on Google Tax Avoidance Scheme: "I Think That You Do Evil." May 16. The Guardian. http://www.guardian.co.uk/ technology/2013/may/16/google-told-by-mp-you- do-do-evil?INTCMP=SRCH.

Cadwalladr, C. 2012. Do Online Courses Spell the End for the Traditional University? November 11. The Observer.

Christensen, C. And H.J. Eyring. 2011. The Innovative University: Changing the DNA of Higher Education from the Inside Out. San Francisco: Jossey Bass. 
Clarke, S. 1982. Marx, Marginalism, and Modern Sociology. Basingstoke: Macmillan.

Collini, S. 2012. What are Universities For? London: Penguin.

Crouch, C. 2011. The Strange Non-Death of Neoliberalism. Cambridge: Polity.

Dupré, J. 1995. The Disorder of Things: Metaphysical Foundations of the Disunity of Science, Cambridge, MA: Harvard University Press.

Daniel, J. 2012. Making Sense of MOOCs: Musings in a Maze of Myth, Paradox and Possibility. Journal of Interactive Media in Education. http:// jime.open.ac.uk/2012/18.

The Disorder of Things. 2012. Open Access: HEFCE, REF2020 and the Threat to Academic Freedom. http://thedisorderofthings.com/2012/12/04/open-accesshefce-ref2020-and-the-threat-to-academic-freedom/.

The Economist. 2012a. Not What it Used to Be. December 1. 405(8813): 55-56.

The Economist. 2012b. Technology Giants at War: Another Game of Thrones. December 1. 405(8813): 27-32.

The Economist. 2013. Generation Jobless. April 27. 407(8833): 9.

Edgecliffe-Johnson, A. and C. Cook. 2013. Education: From Blackboard to Keyboard. January 17. Financial Times.

Elzen, B., F. Geels and K. Green, eds. 2004. System Innovation and the Transition to Sustainability: Theory, Evidence and Policy. Cheltenham: Edward Elgar.

Finch, Dame J. 2012. Accessibility, sustainability, excellence: how to expand access to research publications. Report of the Working Group on Expanding Access to Published Research Findings. London. http://www.researchinfonet.org/ publish/finch/.

Geels, F. 2005. The dynamics of transitions in socio-technical systems: A multi-level analysis of the transition pathway from horse-drawn carriages to automobiles (1860-1930). Technological Analysis and Strategic Management 17(4): 445-476.

Geels, F. 2011. The multi-level perspective on sustainability transitions: Responses to seven criticisms', Environmental Innovation and Societal Transitions 1(1): 24-40.

Hall, S., D. Massey \& M. Rustin. 2013. After Neoliberalism: Analysing the Present. Soundings 1: 8-22.

Harnad, S. 2013. Worldwide Open Access: UK Leadership? Insights 26(1): 14-21. doi: 10.1629/2048-7754.26.1.14.

Harvey, D. 2005. A Brief History of Neoliberalism, Oxford: Oxford University Press.

Heller, M. 2008. The Gridlock Economy, New York: Basic Books

Heller, M. and R. Eisenberg. 1998. Can Patents Deter Innovation? The Anticommons in Biomedical Research. Science 280: 698-701.

Hern, A. 2013. How Can Amazon Pay Tax on Profits it Doesn't Make? May 16. The Guardian. http://www.guardian.co.uk/commentisfree/2013/may/16/amazon-taxavoidance-profits? INTCMP=SRCH.

Hill, P. 2012. Four Barriers That MOOCs Must Overcome To Build a Sustainable Model. e-Literate. http://mfeldstein.com/four-barriers-that-moocs-must-overcome-tobecome-sustainable-model/.

Jessop, B. 2002. Capitalism, the Regulation Approach, and Critical Realism. In Critical Realism and Marxism, eds. A. Brown, S. Fleetwood and J.M. Roberts. London and New York: Routledge. 
Kendzior, S. 2012. The Closing of American Academia. http://www.aljazeera.com/ indepth/opinion/2012/08/2012820102749246453.html.

Kendzior, S. 2013. Academia's Indentured Servants. http://www.alternet.org/education/ academias-indentured-servants.

Kern, F. 2011. Ideas, Institutions, and Interests: Explaining Policy Divergence in Fostering 'System Innovations' Towards Sustainability. Environment and Planning $C$ 29: 1116-34.

Kiplinger. 2012. The Looming Threat of Student Debt. http://www.nasdaq.com/article/ the-looming-threat-of-student-debt-cm 139289.

Larnier, J. 2011. You Are Not a Gadget, London: Penguin.

Larnier, J. 2013. Who Owns the Future? London: Allen Lane.

Mayer-Schönberger, V. and K. Cukier. 2013. Big Data: A Revolution That Will Transform How We Live, Work and Think. London: John Murray.

Mirowski, P. 2011. ScienceMart: Privatizing American Science. Cambridge, MA: Harvard University Press.

Mirowski, P. 2013. Never Let a Serious Crisis Go to Waste: How Neoliberalism Survived the Meltdown. London: Verso.

Mirowski. P. and E.-M. Sent, eds. 2002. Science Bought and Sold, Chicago: University of Chicago Press.

Mirowski, P. And E.-M. Sent. 2008. The Commercialization of Science and the Response of STS. In New Handbook of STS, eds. E. Hackett, J. Wacjman, O. Amsterdamska and M. Lynch. Cambridge, MA: MIT Press.

Mittra, J. et al. 2011. From Maturity to Value-Added Innovation: Lessons from the Pharmaceutical and Agro-Biotechnology Industries. Trends in Biotechnology 29:105-109.

Naughton, J. 2013. Review of the New Digital Age. The Observer. April 28.

Nielsen, M. 2012. Reinventing Discovery: The New Era of Networked Science. Princeton, NJ and Oxford: Princeton University Press.

Nordmann, A., H. Radder \& G. Schiemann, eds. 2011. Science Transformed? Debating Claims of an Epochal Break. Pittsburgh: Pittsburgh University Press.

The Royal Society. 2012. Science as an Open Enterprise, London: Royal Society.

Schmidt, E. 2013. At Google we aspire to do the right thing. So we welcome a debate on international tax reform. The Guardian May 18. http://www.guardian.co.uk/commentisfree/2013/may/18/google-tax-reform-ericschmidt.

Schmidt, E. \& J. Cohen. 2013. The New Digital Age, New York: Alfred A. Knopf.

Sent, E.-M. 1999. Economics of Science: Survey and Suggestions. Journal of Economic Methodology 6:95-124.

Smith, A., J.-P. Voss and J. Grin. 2010. Innovation Studies and Sustainability Transitions: The Allure of the Multi-Level Perspective and its Challenges. Research Policy 39: 435-448.

Smith, A. \& A. Stirling. 2007. Moving outside or inside? objectification and reflexivity in the governance of socio-technical systems. Journal of Environmental Policy and Planning 8(3-4): 1-23. 
Trueman, T. 2013. An Open and Shut Case, or Merely a Gold Meddle? Network-Magazine of the BSA (Spring): 26-31.

Tyfield, D. 2012a. The Economics of Science: A Critical Realist Overview -Volume 1: Illustrations and Philosophical Preliminaries. London: Routledge.

Tyfield, D. 2012b. The Economics of Science: A Critical Realist Overview - Volume 2: Towards a Synthesis of Political Economy and Science \& Technology Studies. London: Routledge.

Tyfield, D. 2012c. A Cultural Political Economy of Research and Innovation in an Age of Crisis. Minerva 50(2): 149-167. 